\title{
Archaeological demography as a tool for the study of women and gender in the past
}

\author{
Jennifer C. French
}

Accepted for publication 19/7/2018 in Cambridge Archaeological Journal

\begin{abstract}
In the last twenty years, demography has re-emerged as a key research area within archaeology. This research has refined archaeological demographic methods and examined the relationships between demographic, cultural, and environmental change. Here, I discuss how the results of the growing corpus of archaeological demographic studies can contribute to gender archaeology, aiding the incorporation of women into narratives of the past. By considering the important role of women in the demographic regimes of small-scale societies, I explain how archaeological demography can provide insights into the behaviour and lives of women, without relying on the often problematic identification of gendered artefacts, activities, and/or places. Archaeological demography as a tool for gender archaeology also permits a move away from the female empiricism of simply adding women into archaeological narratives, to provide an alternative framework for the analysis of gender roles and practices. I demonstrate the feasibility and benefits of this approach using an example from the Upper Palaeolithic of Southwestern France.

\section{Introduction}

Demography has recently re-emerged as a growing research area within archaeology. The results of this research have been two-fold. Much progress has been made in refining and developing archaeological demographic methods, aided by the increased availability and precision of radiometric dates, as well as a growing body of comparative demographic data derived from ancient and modern genetics (e.g. Downey et al. 2014; Porčič and Nikolić 2016; Shennan et al. 2013). Concurrently, theoretical approaches to demography within archaeology have moved away from the Malthusian/Boserupian framework which dominated in the 1960s-1970s to
\end{abstract}


incorporate cultural evolutionary approaches, in which demography- through its impact on social learning, the retention of cultural traits, and the rate of new innovations - is a key variable in processes of social and artefactual change (e.g. Henrich 2004; Powell et al. 2009; Shennan 2002). Demography is so important to current archaeological research agendas that in a recent article outlining the 25 most pressing "grand challenges" for the discipline in the $21^{\text {st }}$ century, six had a demographic basis, ranging from the need to understand the evolution of social group sizes to the demographic processes that drive urbanism (Kintigh et al. 2014).

While the relationship between demographic and socio-cultural change is high on many research agendas, less attention has been paid to the causes of demographic change in the past. Furthermore, where these have been considered, the focus has been on broad climatic and environmental variables, rather than social factors and individual behaviours (Hull 2011). This is unsurprising, given the coarse-grained nature of much archaeological demographic data, and the emphasis on long-term demographic trends. However, a result of this is that archaeologists (myself included) have largely overlooked one key element of their research: the importance of women to the demographic regimes of small-scale societies, and how, as a result, archaeological demography is intrinsically concerned with women. Using demographic principles as a starting point, in this paper, I discuss how archaeological demographic studies can serve as a means of rectifying the often implicit androcentric biases in archaeological interpretation, and be used as a tool for the study of gender in the past- defined here as "the expression of social practices and beliefs about sexual difference" (Gilchrist 1999: x). My focus will be on prehistory, although the principles discussed are not specific to any time period or region. The overall aims of this paper are to provide the theoretical and biological background to the relevance of archaeological demography to gender archaeology, to outline how gender archaeology practitioners can engage with the results of archaeological demographic research, and to explain what is gained from this engagement.

\section{Women's role in the demography of small-scale societies}

The starting point for the use of archaeological demography as a tool for gender archaeology is understanding both the basis of demography, and the different demographic roles, and relative demographic importance, of men and women.

All demographic change ultimately results from variation in one or more of the three processes of fertility, mortality, and migration. For example, populations can change 
in size only if there is an imbalance between the number of births (fertility) and the number of deaths (mortality) (this is termed "natural increase") and/or between the number of people moving in to the population and the number of people moving out (this is termed "net migration"). While the physical movement of people is an important demographic variable, in the relatively small and closed populations typical of much of the past, long-term variation (i.e. over multiple human generations) in rates of natural increase, rather than in net migration, would have been the primary cause of changes in overall population size (Hinde 2002:33).

The number and relative frequencies of births and deaths drive population change but not all births and deaths have an equal impact. This is because men and women participate differently in demographic regimes and some members of a population are more important demographically than others. The effects of these are particularly pronounced in small-scale natural fertility populations ("natural fertility" refers to the absence of both modern contraceptives and adjustments to reproductive behaviour in view of a target family size: Wood 1990: 212-13). This concept is best explained with an example: compare the demographic impact on a small-scale, natural fertility population of the death of a 60-year-old man, and the death of a woman in her 20s. The death of the 60-year-old man would directly subtract one member from the population, and may adversely affect the lives (including the continued survival) of any dependents for whom he is responsible or provides. He is unlikely to have any more children, although it remains a possibility. Overall, this death would have very little effect on the size of a small population, and is unlikely to have any long-term repercussions. In contrast, the death of the woman in her 20s would have a much more sustained impact. In extant small-scale societies, most women in their 20s have at least one child. If that child were still being breastfed, it would almost certainly die with its mother, and even the survival of older children can be at risk. In this case, the death has directly subtracted multiple members from the population. In addition, as the woman is only in her 20s, and is biologically able to have children for up to 20 more years, the population has also lost any subsequent children she was very likely to have, as well as the potential future children of any of her earlier children who did not survive into adulthood; her death thus having indirect effects with long-term implications for the population.

An excellent example of the contrast between the importance of men and women can be seen in the demographic consequences of raids and warfare in small-scale societies. Simulations based on demographic data from Hadza hunter-gatherers in Tanzania show rapid population decreases if only $10 \%$ of the women aged $15-45$ are 
removed (taken away or killed) from the population every year. Occasional raids once a decade which remove $22 \%$ of women and children are sufficient to render the population stationary. In contrast, the loss of only men has little direct effect (Blurton Jones 2016: 221-223). In short, in determining population size and growth, female fertility and mortality, along with the mortality of infants and children, are the key factors, with the fertility and mortality of men playing a much lesser role. Women are the drivers of population change, and their behaviour and other aspects of their lives are important determinants of both their fertility and infant and child mortality.

While the scenarios outlined above derive from studies of extant small-scale societies, these principles apply equally to past populations. This is because of the uniformitarian nature of demography (Howell 1976). At least as far as a common biology is shared (i.e. for all Homo sapiens populations) we can assume that the basic processes relating to fertility and mortality are similar, that they respond to variations in the social and natural environment in the same way, and that these similarities act as constraints and impose limits on demographic behaviours. Recognition of the central role of women to demographic change provides the basis for the relevance of archaeological demography to gender archaeology.

\section{Gender, sex, and reproduction in archaeological theory}

The field of gender archaeology initially grew out of the recognition of the implicit (if not necessarily always explicit) absence of women from much archaeological interpretation and representation (Conkey and Spector 1984). Over 30 years later, this continues to be the case in many areas of archaeological research, particularly in early prehistory (Bolger 2006, 2013; Conkey 2013). This absence can be explained through the twin issues of the perceived invisibility and the unimportance of women.

The issue of visibility refers to the long-standing default position that the archaeological record is the product of men and is formed primarily as a result of male behaviours (Conkey and Gero 1997). While the presence of men is assumed, in contrast, women must be proven as active contributors to life in the past (e.g. Fleming 2006:275). The search for the 'proof' of women relies on the gender attribution of artefacts and activities, the burial record (i.e. grave goods associated with clearly sexed individuals) or perceived limitations which restrict possible roles and social behaviours (Brumfiel 2006: 37-43). The behaviours attributed to women in many archaeological contexts contribute to the pattern of invisible women with 'female activities' largely restricted to domestic settings, and 'female artefacts' 
predominantly manufactured from soft materials which leave fewer archaeological traces (Owen 2005: 36-37). In addition, the types of artefacts and activities attributed to women are frequently considered unimportant compared to those which by default are classified as male. For example, when women are acknowledged as possible manufacturers of lithic artefacts, they are often limited to expedient, unskilled technologies rather than the highly-skilled technologies that result in formal retouched tools (Arthur 2010; Finlay 2013; Gero 1991).

There are many problems with gendering activities and artefacts, including the ethnocentric assumptions on which such attributions are often based (Dobres 2004). In particular, these attributions lend themselves to a 'natural' or essentialist perspective on gender roles in the past, emphasising the supposed universality of gender traits (Conkey and Spector 1984). If women's roles are seen to be difficult to reconstruct, unimportant, restricted by biology, and broadly static both chronologically and geographically, they cannot-unlike men- be viewed as productive agents in the archaeological, responsible for the material we excavate and for the changes and developments in past societies (Wylie 1991:34). Nevertheless, such attributions continue to be made. Archaeological demography as a tool for the study of women and gender in the past obviates many of these problems. Nonetheless, using demographic principles as a framework for incorporating women into archaeological interpretations requires caveats, particularly regarding how this approach aligns with gender theory both in archaeology and allied disciplines.

Firstly, the implicit focus is on women's reproductive role; an approach which appears at odds with most research in gender archaeology. The focus on physiological differences between men and women, and the prominence accorded to women's role in childbirth and childrearing are hallmarks of earlier androcentric studies (Conkey and Spector 1984; Joyce 2008: 8-10). Differences in biology and reproductive roles were used to justify interpretations of the past in which men were active social agents and women were passive biological agents. This position is implicit in the few studies which exist on fertility in prehistoric societies, which use women's demographic roles either to focus on men's control over women or set up a dichotomy between the 'dependent female' and 'provisioning male' (e.g. Bentley 1996; Mussi 2007). However, regardless of its misuse in earlier androcentric studies, reproduction is an important and unavoidable part of the lives of women in natural fertility populations, and, on this basis alone, should not be neglected (Whitehouse 2007:34-36). 
Secondly, the use of demographic data, in common with other forms of archaeological data which have a biological basis (e.g. osteological contexts), is particularly susceptible to the "binary binds" (Ghisleni et al. 2016) of interpretation typical of second-wave gender research. There are two binaries: one that stems from the notion that there are only two sexes (male/female), and one from a nature/culture distinction between 'sex' and 'gender', with sex being a biological certainty and gender a cultural construction. These two binaries converge on a two-sex, twogender model (Joyce 2008:18) in which sex becomes a proxy for gender. More recent third-wave research has criticised both binaries, arguing against their heteronormative assumptions and static views of gender. Indeed, much third-wave gender research in archaeology and allied disciplines is explicitly concerned with moving beyond these binaries, emphasising the fluidity of gender, sex and gender as a continuum of possibilities, and taking an increasingly intersectional view of gender in which the role of factors such as age, sexuality, and social class in constructing identity are also considered (Aimers and Rutecki 2016; Ghiselni et al. 2016; Geller 2009; Stratton 2016). As part of this plurality, there has been a clear move away from a focus on the study of women, to the study of men, women, and multiple genders (Bolger 2013).

Without ignoring both these theoretical advances and their legitimate criticisms of a simplified approach to the study of women and gender in the past, a case can still be made for a focus on women's roles, as well as adherence to the binaries of secondwave approaches, providing we are cognizant of their limitations. While there is a growing consensus among gender archaeologists that we have moved beyond the issue of the visibility of women in archaeological interpretations (e.g. Bolger 2013: 89; Joyce 2008:114), I am less convinced that this can be said of all periods, particularly early prehistory (see discussion below).

It is important to remember that the study of women is not the same as the study of gender (Whitehouse 2007). While the demographic approach advocated here is primarily concerned with the archaeological visibility of women and the importance of women to demographic processes, this does not mean that any demographic study, archaeological or otherwise, automatically informs on gender on a societal level (Riley 1998, 1999). However, gender can be examined from demographic studies. Many features of women's lives are affected by wider societal gender ideas and practices, including their rights, employment, and well-being; factors which have clear import to demographic variables, including fertility and mortality (Riley 2005). Similarly, while a demographic approach takes fertility as its starting point, it 
does not restrict the study of women behaviours and actions to their biological choices, nor only offer insight into women as a biological category: both biology and culture are integral to demographic processes (Roth 2004; Sear et al. 2016).

The primary limitation of this approach is its propagation of a binary two-sex, twogender model which may not necessarily reflect the full remit of gender relations in all past societies, and which furthermore, presents a limited view of 'women' as those who are fertile and of childbearing age. Nonetheless, I do not argue that gender is limited to these two categories, or that biological sex is always an accurate proxy for gender; just that male and female reproductive roles are generally recognised within gender systems in some way. It is my contention that these caveats are outweighed by the methodological approach to gender archaeology which this demographic framework provides; a useful addition to a field characterised by long-standing tensions between a growing body of theory and a limited methodological tool kit (Hill 1998).

\section{A framework for inferring women and gender from archaeological demographic studies}

Archaeological demography uses proxies including summed probability distributions of ${ }^{14} \mathrm{C}$ dates [SPDRD], settlement sizes, and numbers of archaeological sites, to document long-term chronological and geographical trends in relative population size, density, and growth (Chamberlain 2006; for an example see Figure 2 , this paper $)^{1}$. As women are the drivers of population change in small-scale societies it follows that the long-term patterns we see in archaeological demographic studies are documenting changes in the demographic behaviour of women. Taking this one step further, these patterns can also be viewed as records of shifts in gender and social relations which are either a cause or consequence of these demographic changes. In this sense, demographic patterns become an archaeologically-visible material aspect of women's behaviour and of gender in the past.

The key difficulty is reconciling the chronological scales of individual human behaviour and long-term trends. The fundamental time-scale of population dynamics is generational (20-30 years) which is impossible to document with the chronological resolution offered by the archaeological record. In addition, information about the specific processes of fertility, mortality, and migration is lacking. However, knowing the exact rates of change in these demographic variables is less important than recognising the directionality and the magnitude of the changes which the uniformitarian nature of demography tells us must lie behind 
long-term population growth and size patterns. We can infer change in women's social and demographic behaviours from patterns of collective population change. To do this we need to understand the relationships between women's behaviour and variation in the most important demographic variables: fertility and infant and child mortality.

Demographic studies of contemporary small-scale natural fertility populations provide an excellent database for understanding these relationships. Underpinning many of these studies is the importance of women's energetics to patterns of fertility and infant mortality. Among contemporary small-scale populations, women's energetics is studied largely within the paradigm of human behavioural ecology (specifically evolutionary demography and life history theory), often focusing on the (conscious or unconscious) ways in which women adjust their behaviour to maximise their reproductive success ('fitness')2 (e.g. Blurton Jones 2016; Hill and Hurtado 1996). Here, I am less concerned with the notion of fitness-increasing behaviour, or whether any choices were intentional or not. Rather, I wish to draw attention to the interplay between biology, the social and demographic behaviour of women, and population outcomes.

Women's energy, behaviour, and demographic outcomes

The starting point of this interplay is understanding how women's energy influences fertility and juvenile mortality in natural fertility populations. The basic principle is that reproduction is energetically expensive and places strong energetic demands on a woman, both to support the pregnancy, and then to support the subsequent lactation required to feed the child (Butte and King 2005). In essence, while a woman is pregnant and breastfeeding, she is "metabolizing for two" (i.e. for both herself and the foetus, and then, following the birth, the child: Ellison 2001:94). Each successful pregnancy requires an estimated additional 50,000 calories above normal metabolic requirements, with breastfeeding alone requiring an additional 500-1000 calories of energy per day (Frisch 2002:8-9). In natural fertility populations, the energetic constraints of having a child can be severe: among the Ju/'hoansi (!Kung) of Botswana, fertile women are likely to be either pregnant or lactating at almost all times during their childbearing years (Howell 2010:38). In short, energy plays a key role in a woman's reproductive function (see Ellison 2001 for an account of the exact physiological and hormonal mechanisms behind this) and reproductive function responds (within limits) to conditions of the social and natural environment (Jasienka 2003) ${ }^{3}$. The relationship between women's energy and reproductive function impacts fertility by affecting the probability of a pregnancy occurring (the 
rate of conception), and the time between successive pregnancies (through its effect on the length of the period of lactational amenorrhea or temporary infertility due to breastfeeding), and impacts infant mortality by influencing infant birth weight.

This allows us to make some simplified predictions about the relationships between energy intake, energy expenditure, and fertility and infant/child mortality in natural fertility populations (Figure 1). Higher levels of energy expenditure of women should correlate with lower fertility and reductions in energy expenditure with higher fertility. Data from recent hunter-gatherer populations support this correlation, when energy expenditure is measured both in terms of residential mobility, and activity or workload levels (e.g. Binford and Chasko 1976; Marlowe 2001; Pennington 2001; Page et al. 2016; Roth 1985 cf. Early and Headland 1998). Similarly, increased energy input should correlate with increased fertility and decreased energy input with decreased fertility. Several studies of foragers support this link using resource abundance measures, including environmental data and women's body weight ${ }^{4}$, as proxies for energy input (e.g. Blurton Jones 2016:121 [but see ibid: 329]; Helle and Helama 2007; Hill and Hurtado 1996:348; Marlowe 2001; Page et al. 2016). However, the relative importance of energy expenditure and input to fertility can be difficult to untangle: for example, the low fertility rate of the $\mathrm{Ju} /$ 'hoansi (in comparison with other natural fertility populations) has been attributed to both women's workload constraints (Bentley 1985; Blurton Jones 1987; Hames and Draper 2004) and limited calorie intake (Howell 1979: Chapter 10; Wilmsen 1982).

\section{[Figure 1 here]}

While the relationship between women's energy and infant mortality is a product of overall energy balance, it is most often examined with regard to the effect of maternal diet and nutrition. As a rule, underweight or energy-deprived mothers have babies born at lower birth weights (Frisch 1994:115). Worldwide, low birth weight is a major predictor of infant mortality (United Nations Children's Fund and World Health Organisation 2004). Low birth weights are also more common among pre-term infants (babies born before 37 weeks of pregnancy); a factor which is also linked to low energy availability (Ellison 2003:346; see also Dunsworth et al. 2012). A good example of this connection between maternal and child health is seen among the Pumé of Venezuela. Here, infant mortality rates of the Savannah (huntergatherer) Pumé and the river (horticultural) Pumé were significantly different (rates of 346 and 132 per 1000 live births respectively), despite similar access to modern medical care (Kramer and Greaves 2007). The researchers attribute the reduced 
infant mortality rate of the river Pumé to the effect of greater overall maternal body mass and lack of periods of nutritional stress and weight loss, caused by a more reliable food supply.

In sum, the relationship between women's energy and reproduction affects three key biological processes that influence fertility and infant mortality, and ultimately population growth and size. While the mechanisms through which the relationships between women's energy, fertility, and infant mortality operate are primarily physiological, we should not underestimate the role of behaviour and culture. Sear et al. (2016) provide an excellent summary of this balance between behaviour and biology in their discussion of the decisions which affect how many children a woman has (total fertility). While sufficient energy reserves are required for a woman to successfully have a child, total fertility is the product of both her physiological condition and multiple interrelated decisions. Assuming a woman is both biologically able to and wishes to have children, these decisions include: when to have the first child, when to stop having children, the ideal gap between children, when to partner and with whom, and whether to break-off a partnership (and possibly to re-partner). Furthermore, these decisions do not occur in a vacuum but are influenced by factors such as social norms surrounding reproduction and family structure, as well as more individual factors such as upbringing and behaviour of friends and family. Certain behavioural decisions (for example, whether or not to have children and when) admittedly represent less distinct choices in natural fertility societies than they do when effective contraception is available. Nonetheless, even in natural fertility societies, women are constrained by biology in their demographic choices, not controlled by it. Both biology and culture are crucial to demography and we cannot explain or analyse demographic data without taking both into account (Roth 2004).

Crucially, even while women's energy is demographically important due to its physiological effects, the relevant mechanisms are responsive to behaviours which affect both energy intake and expenditure (Dufour and Sauther 2002). The quantity and quality of available food resources (energy intake) and the mobility and workload patterns (energy expenditure) of women are both constrained and influenced by their social and physical environment. As discussed above, these environments, in turn, affect women's behaviours and decisions which further influence the number of children women have, and the survival rate of these children. Table 1 provides examples of cultural factors which influence women's energy availability and resultant fertility/infant mortality. 
These cultural factors can often combine with physiology to intensify directional demographic changes. A good example of this is Kramer and McMillan's (2006) study of longitudinal fertility changes among the Xculoc Maya, a group of subsistence maize farmers from the Yucatan peninsula. The introduction of a waterpump and mill in the 1970s increased women's labour efficiency reducing the time spent in economic activities, and as result, reducing energy expenditure. The Xculoc Maya women chose to reallocate their new-found spare time to less strenuous leisure activities, resulting in further reductions in energy expenditure.

Concurrently, the introduction of this labour-saving technology reduced the importance of the economic contribution of women. This, in turn, led to women being encouraged to leave home and marry at a younger age. The combination of these physiological and cultural changes led to a drop in the average age of first birth; a common predictor of overall total fertility in natural fertility populations. This was indeed the case among the Xculoc women, where following this first early birth, the effect of these cultural and technological changes was an increased probability of conception at all ages, and higher overall completed fertility (number of children).

\section{[Table 1 here]}

This example also serves to remind us that cultural and societal norms affect many of the variables listed in Table 1, determining such factors as who performs which tasks, how living arrangements are structured, and who gains access to critical dietary resources. It is here where gender becomes important. Many features of the social environment are gendered, and their examination is not linked to the exclusive study of women, but also the interaction and relationships between different groups. Spielmann (1989), for example, highlights how social food taboos on women at key reproductive stages (e.g. menarche, pregnancy) as well as differential access to food resources between women and men in multiple huntergatherer societies, contributes to nutritional stress among women, with knock-on effects for fertility and infant mortality. Marlowe's (2001) study of hunter-gatherers showed that increased male provisioning to diet increased overall female fertility either through allowing for earlier weaning of children, or through permitting women to spend less energy by reducing their overall foraging workload. Shennan (2002: Chapter 7) has suggested that this relationship would likely influence the choice of partners by women in small-scale societies; we could hypothesise that if this were the case, this would lead to or further entrenched gendered divisions of labour or food getting tasks in a sort of feedback loop. 
The extent to which energetics explains any demographic patterns depends on the importance of this constraint on the local population. Specific social practices, such as the frequency and duration of marriage and the availability of suitable marriage partners, explain much fertility variation among modern-day contracepting societies (Sear et al. 2016:5), and are also key considerations in ethnographic natural fertility societies (e.g. Panter-Brick 1997:235). However, based on comparisons with recent populations, it seems safe to assume that energetics played a fundamental demographic role in the past (e.g. Kelly 2013: 213), and that women were aware of the connection between their energetic status and reproductive outcomes. Furthermore, from an archaeological perspective, a focus on energetics has the additional advantage that many of the associated behaviours, such as mobility and diet, are directly inferable from the archaeological record.

\section{Application to archaeological contexts}

The relationships between women's energy and fertility (and to a lesser extent, infant and child mortality) have been fundamental in archaeological explanations of demographic change associated with the transition from hunting and gathering to farming, frequently referred to as the Neolithic Demographic Transition [NDT] (Bocquet-Appel 2002, 2008, 2011). Archaeological evidence, including summed probability distributions of radiocarbon dates, skeletal assemblages, and changing site sizes, documents a marked increase in world population growth and size driven by an increase in fertility (e.g. Downey et al. 2014), followed by a subsequent increase in mortality and morbidity (poor health) (e.g. Bocquet-Appel and Bar Yosef 2008). This shift from a hunter-gatherer economy to an agriculture economy is characterised by shifts in mobility and technology, as well as subsistence; variables which have been proposed as both the cause of the initial increased in fertility, and the later increase in mortality (Lambert 2009) (see Shennan 2018 for a comprehensive archaeological treatment of evolutionary demography and the NDT).

Following the principles described above, proponents of the NDT argue that sedentism permitted the initial fertility increase, with decreased mobility and the concomitant reduced need to carry children while moving camp reducing women's physical energy expenditure. The adoption of agriculture added to this shift in women's workload and nutrition, providing an increase in calorie-rich foods, and a food resource which potentially permitted earlier infant weaning, leading to short birth intervals between children; two factors which likely contributed to fertility increases (Bocquet-Appel 2008). Concurrently, sedentism and increased population density reduced health through facilitating the spread of bacteria and pathogens, 
increasing mortality rates (Cohen 2008). Results of recent ethnographic fieldwork about the Agta of the Philippines (a hunter-gatherer population whose groups vary in their degree of sedentism and practice of cultivation) provide compelling evidence in support of this NDT scenario (Page et al. 2016).

\section{Demography, women, and gender in the Upper Palaeolithic}

The Neolithic Demographic Transition has to date been the research area where the intersection between demography and women's energy has been most thoroughly explored. In the Pleistocene, this intersection has also been examined in terms of wider trends in hominin evolution (e.g. Aiello and Key 2002; Snodgrass and Leonard 2009). However, specific references to women's lives and behaviours, and especially gender, are limited (Peterson 2010: 254; for a discussion on gender in early agricultural societies based on non-archaeological data see Hansen et al. 2015). While there is some conjecture involved, one of the main advantages of this demographic approach is that it forms a useful tool in instances where the data required to examine gender through more conventional archaeological methods are lacking. Using data from the Upper Palaeolithic (ca. 40 000-12 000 cal BP) of Southwestern France, here I provide a brief demonstration of interpretation.

The Palaeolithic has long been recognised as particularly susceptible to androcentric interpretations (Conkey and Spector 1984:6). More so than any other period, women are still implicitly (if not explicitly) absent from much archaeological interpretation and representation, and gender is frequently ignored in discussions of Palaeolithic society. This can partly be explained by the coarse resolution of many Palaeolithic sites and contexts, which discourages the broader consideration of individuals and agency (Conkey 1991: 57-58; Dobres 1995). The neglect of women and gender is also compounded by several other features of the record, and long-standing assumptions about the nature of Palaeolithic life including; an impoverished material culture and burial record (which largely prevents the application of some of the more nuanced approaches to gender developed in later periods); persistent "Man the Hunter" narratives of subsistence and social organisation (Conkey 2013; Hager 1997; Zihlman 1997, 2013); and assumptions that men were the primary manufacturers of both the stone tools which dominate the record (Arthur 2010; Gero 1991; Finlay 2013;

Brumbach and Jarvenpa 2006) and the impressive parietal and portable art of the Upper Palaeolithic (Fritz et al. 2016: 1310-1316; Gifford-Gonzalez 1993:37; McCoid and McDermott 1996). The question has also been raised as to whether gender as a symbolic and cultural concept could have existed in earlier Palaeolithic archaic 
hominin societies (Balme and Bowdler 2006; Conkey and Gero 1997: 418; Dobres 2004).

Figure 2 presents the results of an archaeological demographic study of the population history of the Upper Palaeolithic hunter-gatherer populations of Southwestern France (French and Collins 2015), using summed probability distributions of radiocarbon dates [SPDRD] as a demographic proxy and comparing this distribution to the global temperature variations documented in the NGRIP ice core (Andersen et al. 2006). The use of radiocarbon dates as a demographic proxy in archaeology was pioneered by Rick (1987), and has been subsequently developed into a popular and robust method for analysing long-term demographic trends.

\section{[Figure 2 here]}

The premise of the method is straightforward: because more people produce more datable material (i.e. cultural carbon), relative temporal changes in the frequency and distribution of ${ }^{14} \mathrm{C}$ dates should reflect corresponding proportional variations in past population sizes and densities, with peaks indicating periods of increased relative population, and troughs indicating periods of decreased population. However, there are well-documented biases which can intervene with the above assumption, and past behaviours could have altered the simple correlation between number of people and the strength of the ${ }^{14} \mathrm{C}$ signature (Williams 2012). There were several ways in which the effects of bias were tested and accounted for in the distribution presented in Figure 2. Firstly, site-specific Bayesian models and outlier analysis were used to 'correct' the effect of unreliable or erroneous dates on the pattern produced. Secondly, the probability distributions calculated for each date were normalised through averaging within sites to prevent well-dated sites being over-represented and driving the resultant distribution. A simulated dataset was also created to test against the resultant SPDRD to ensure that the signal produced was not simply a reflection of the radiocarbon calibration curve. The effect of timetransgressive taphonomic loss of quantities of datable material is harder to assess, but in this case the data suggest that taphonomic bias had little effect on the overall radiocarbon date distribution (see French and Collins 2015 and supplementary material for a detailed discussion). As with much palaeodemographic research using SPDRDs, the main source of uncertainty is the possible influence of chronological changes in mobility/land-use strategy on the shape of the distribution (e.g. Attenbrow 2006; Naudinot et al. 2014). While this possibility cannot be excluded, the broad correspondence between the shape of the SPDRD and the chronological distribution of another common palaeodemographic proxy (archaeological site 
counts) strengthens the interpretation of relative demographic change as the cause of the observed pattern (French 2015; French and Collins 2015).

The demographic pattern documented in Figure 2 is highly variable, showing numerous peaks and troughs in relative population size over the course of the Upper Palaeolithic in Southwestern France. While migration may also play a role (a point to which we will return), in keeping with demographic theory, it is assumed that long-term fluctuations are primarily driven by changing patterns of fertility and/or mortality, of which infant and child mortality would have the biggest impact. Following the assumptions outlined above, Figure 2 therefore presents a long-term record of changes in women's demographic behaviour. The most important initial benefit of this approach is that it automatically prevents us from falling into the common trap of viewing women's behaviour (and following that, gender roles and relations) as inherently static (Wylie 1991:34).

What do we know about the lives of women and of gender relations in the Upper Palaeolithic in Southwestern France? We will focus on the later part of the sequence: the Magdalenian and Azilian, which covers the period from after the last glacial maximum to the end of the Pleistocene. Very few studies move beyond the general assumptions described above which characterise the Palaeolithic as a whole: that men hunt, while women gather, that men made stone tools, and women manufactured or worked with perishable items (nets, traps, furs). Even those works which explicitly examine or critique these assumptions often still ultimately rely on the gendering of artefacts or activities to inform on women in the Magdalenian (e.g. Keeley 2010; Owen 2005; see Conkey 1991 for a counter-example). Rare examples of skeletal remains and other direct biological markers of women provide 'snap shots' of women's lives during the period. For example, the rich set of grave goods found with the skeleton of a Magdalenian woman at the site of Saint-Germain-la-Rivière has been interpreted as indicating a privileged social status (Vanhaeren and d'Errico 2005). Measurements of hand stencils and finger flutings in caves walls provide direct evidence of women as producers of some of the famous late glacial art in the region (Snow 2006; Van Gelder and Sharpe 2009).

There are two main problems with the above examples. Firstly, they are either too generic in their envisioning of women and gender relations to tell us anything about these variables in the Magdalenian of Southwestern France, or they are too specific and tied to one individual or site. Secondly, they still work on the assumption that we require 'proof' of the presence of women in the archaeological record (in a way 
that is not required of men) in order to say anything about their lives. The demographic data presented in Figure 2 obviates these problems.

As is the case throughout the Upper Palaeolithic sequence, population size fluctuates considerably throughout the Magdalenian and Azilian. Given that this period spans many thousands of years, as well as many climatic and cultural shifts, this is unsurprising. Let us focus specifically on the period of population growth $\sim 19000$ cal BP, culminating in the peak documented $18000 \mathrm{cal} \mathrm{BP}$. Examining this peak in its wider archaeological context allows us to hypothesis about the changes in women's lives and in gender relations, which either brought about, or reflect, this demographic change.

The climatic and environmental context is an excellent starting point as resource availability and distribution affect variables relevant to both energy input and energy output, such as food and mobility (Table 1 ). The population growth $\sim 19-18$ 000 cal BP occurred during the early stages of Heinrich event 1 and Greenland Stadial 2 although at a finer-scale it notably correlates with a period of warming within this cold phase (Figure 2). This relative (if slight) improvement might be important, due to the link between increased fertility and increased resource abundance, for which temperature can act as a reasonable proxy. At a broad scale, climatic conditions also affect forager mobility, with increased residential mobility often acting as a buffering response against resource uncertainty and decreased productivity which can be caused by climatic cooling (Grove 2009). In this instance, relative warming may have led to a reduction of residential mobility of Magdalenian women (and hence a reduction in energy expenditure and resultant fertility increases). However, we need to be careful not to read too much into this scenario: comparisons of the relationship between prevailing climatic conditions and population across the complete Upper Palaeolithic sequence shown in Figure 2, revealed a negative (and counter-intuitive) relationship between population and temperature (French and Collins 2015), and the relative impact of temperature increases on local environments is difficult to assess. Other variables which affect women's energy should be considered.

Results of a recent dating programme suggest that the period $\sim 19000-18000 \mathrm{cal}$ BP corresponds with the start of the Middle Magdalenian in the region (Barshay-Szmidt et al. 2016 cf. French and Collins 2015). Several technological and economic changes are reported for this period, including the increased standardisation of lithic tool kits, increased distances of lithic raw material transfer, increases in the intensity of bone and antler working, a change in hafting type, and the appearance of spear 
throwers (Langlais et al. 2016; Langley et al. 2016; Pétillon 2016). In the neighbouring region of the Pyrenees, Langlais (2011) has interpreted these changes as reflecting the increased sedentism of nomadic groups. He contrasts the standardisation of Middle Magdalenian lithics with the more flexible technological strategy seen in the Lower Magdalenian which was designed to minimise risk of tool failure among more mobile populations. Langlais also suggests that lithic production has been divided into two technological domains: one for hunting tools and one for what he terms "domestic" tools, and that the increase in lithic raw material transfer suggests changes in the territorial organisation of local groups.

Many elements of this evidence could account for the changes in women's energy which lie behind the demographic pattern. Increased sedentism would decrease women's energy expenditure, contributing to fertility increases and population growth. Wider exchange networks might improve economic security, limiting the negative demographic impact of food shortages both on fertility, and indirectly on infant/child survival rates. The addition of the spear thrower into the technological repertoire, and the possible distinction between hunting tools and those for other purposes might have improved the hunting yield available to group members and/or reduced the effort spent in hunting 5 . More speculatively, one could posit a scenario whereby women became primarily responsible for the manufacture of the bone and antler tools; an economic activity which requires less physical exertion than hunting and gathering, and for which the intensification of use and production broadly coincides with the demographic peak documented.

This brief example illustrates the ways in which demographic data, used in conjunction with data on classic archaeological variables such as economy, subsistence, and mobility, can serve as a tool to study women and gender in the past. While some of the specifics of the, admittedly simplistic, scenarios outlined above are often difficult to prove they are firmly grounded in biological principles, and permit informed theorisation about the changes in women's lives which would manifest in demographic outcomes. Furthermore, this demographic approach has moved the discussion of women's roles and gender immediately beyond the standard Palaeolithic interpretations, allowing for the consideration of a wider range of possibilities.

A few caveats are noteworthy here. The first is that interpretation in these terms relies firstly on the accuracy and reliability of the demographic reconstruction. In small populations, such as those which characterised early prehistory, stochastic or random variation is also an important factor in population fluctuations, although in 
the long-term, these are likely to be smoothed out. The second is the effect of factors other than those related to women's energy on the demographic patterns seen. In terms of the effect of social choices and behaviours, such as changes in marriage practices, we are left in the familiar archaeological scenario of being unable to test such hypotheses with the available data. Nonetheless, these social variables might be particularly profitably included in the analysis in instances where the results of archaeological demographic studies show a period of relative population change, but no concomitant changes in the more archaeologically visible variables related to changes in women's energy (such as mobility, activities, climate, subsistence) which would support the interpretation of the demographic pattern along these lines.

A more problematic source of equifinality of interpretation is the effect of migration on patterns of relative population size. The possibility that changes in migration rather than natural increase are the cause of population fluctuations is particularly pertinent for Southwestern France as this region acted as a population refugium during the last glacial maximum, and could well have functioned in a similar manner during other Late Pleistocene cold stages (French and Collins 2015). However, testing these alternatives is difficult and the relevant variables of fertility, mortality, and migration are often not directly measurable from the archaeological record. For example, even where large skeletal assemblages are available from which age-at-death distributions can be created, the calculation of mortality rates in archaeological contexts is fraught with difficulties (Meindl and Russell 1998). We are on a slightly firmer footing with fertility. As the birth rate has a stronger effect on population age structure than the death rate (Sattenspiel and Harpending 1983) the ratio of adult to child burials can act as a broad proxy for fertility measures (BocquetAppel and Masset 1982; McFadden and Oxenham 2018). Incontrovertible evidence of large-scale migration into an area might include the sudden and widespread appearance of novel material and behavioural forms, and/or biological or genetic evidence for incoming groups who differ from those seen in the region before (for example, with regard to isotopic signatures, haplogroups etc.). The archaeological signature of a migration out of a region is less clear, but could include the abandonment of settlements, a reduction in cemetery size, or the absence of specific social groups in skeletal assemblages (e.g. Baitzel and Goldstein 2016; Burmeister 2000; Furholt 2018; Price et al. 2002). In any event, no direct data on fertility, mortality, or migration are available for the current case-study, and are likely to be sparse across much of prehistory, at least until the establishment of more permanent settlements and attendant cemeteries. This is particularly unfortunate, as it is these early stages of human prehistory which arguably have the most restricted view of 
women in the past, and have the most to gain from the interpretative approach advocated here. The inability to distinguish between net increase and net migration as a cause of population patterns is seen across many palaeodemographic studies (e.g. Porčič and Nikolić 2016). Until this can be resolved, I suggest that in most archaeological contexts the null hypothesis should be changes in fertility and/or infant child mortality as the primary cause of the population change given that in the long term (i.e. over centuries or more) "natural increase almost invariably dominates net migration" (Hinde 2002:33).

\section{Conclusion: Demography and Gender}

Archaeological demography is a research area which has much to offer to the study of women and gender in the past. The long-term patterns of population change documented through archaeological demographic research are the outcome of multiple individual demographic decisions and processes, driven by changes in female fertility and infant and juvenile mortality. Changes in the number of children that women in small-scale natural fertility population have, and the survival of these children, are strongly linked with both the lives and behaviour of women, and gender relations and practices in the societies in which they live. As such, correlations between demographic events and changes in other variables, including settlement patterns, diet, mobility, and environment, should be interpreted with explicit reference to the shifts in the social, economic, or political lives of women which either brought about or reflect this demographic change, and which can, properly contextualised, inform on gender relations in the past. While this is arguably quite a broad research strategy, as an addition to the gender archaeology tool kit, archaeological demography has two clear additional advantages: it does not rely on questionable notions of gender attribution of artefacts or activities derived from ethnographic comparisons, and it allows for the consideration of gender and women's roles in periods or regions where other lines of evidence (such as mortuary remains) are lacking. The adoption of this approach would also benefit archaeological demography, a field whose interpretative focus often ignores social factors in the explanation of demographic change and is dominated by economic models of carrying capacity and environmental constraints (although I am not advocating for the irrelevance of these variables, nor suggesting that they be abandoned to concentrate solely on women's behaviour).

One of the biggest challenges with this line of enquiry is chronology. It is often difficult to demonstrate correlations between demographic shifts and shifts in behaviours and/or environment, let alone be in a position to distinguish between 
cause and effect. While this challenge is more surmountable in later contexts than in the Palaeolithic example discussed here, it still poses unfortunate limits on the analysis of the relationships between demographic change, women's lives, and gender relations in the past. The uniformitarian nature of demographic processes, nonetheless allow for the development of plausible inferences grounded in demographic and biological theory. Furthermore, what we lose in our understanding of the exact mechanisms of cause/effect we gain in the exploration of longer-term trends. At this early stage of the pursuit of this line of enquiry this seems like an acceptable compromise, especially in light of the very static view of women's behaviour and gendered practices which continues to characterise much prehistory.

Explicitly linking individual reproductive behaviours, and the social environment in which they occurred, with the visible results of long-term population change is also an important methodological consideration. One promising approach is the use of agent based modelling, as employed by Read (2003) in his simulation of decision making, birth spacing, and marriage rules among !Kung San women. Another relevant development is the improvement of techniques to reconstruct breastfeeding and weaning practices (and, from there, infer the fertility variable of inter birth intervals) from osteological remains in archaeological contexts (King et al. 2017; Tsutaya and Yoneda 2015). The more frequent use of SPDRDs to explicitly measure population growth rates, rather than just changes in relative size/density (e.g. Brown 2017; Kelly et al. 2013; Zahid et al. 2016), is also a welcome development; the relationship between changes in fertility/mortality rates and population growth being more direct than the relationship between these variables and population size. Finally, the increased engagement by archaeological demographers with evolutionary demography and life-history theory (as promoted by Shennan 2018) is a vital step towards the development of further methodologies examining the crucial link between reproductive behaviours, culture, and long-term demographic trends.

Women are the drivers of demographic change and are therefore intrinsic to the results of demographic research. The uniformitarian nature of demographic processes means that archaeological demographic data a priori invoke women in their analysis. Furthermore, the dynamic nature of demographic processes and the archaeological focus on regional population change prevents the assumption that womens' roles in the past were static, or that gender relations and practices were the same in all past societies. Through explicitly acknowledging the fundamental role women play in demographic regimes, archaeological demography can help move us 
away from simply 'finding' women; restoring them to their rightful place as obvious and active contributors to both past societies and the resultant archaeological record, and providing a framework in which gender can be examined within a growing area of mainstream archaeological enquiry.

\section{Endnotes}

1. Here I distinguish between archaeological demography in which material culture is used to address demography (sometimes referred to as regional settlement demography; Drennan et al. 2015) and palaeodemography which uses skeletal remains. Archaeological demography focuses primarily on the reconstruction of relative temporal and chronological variations in relative population size and density, while palaeodemography focuses on the reconstruction of age at death profiles for skeletal assemblages from which fertility and mortality can be inferred.

2. The emphasis on fitness-maximisation is central to much earlier work in evolutionary demography and life history theory, as well most research on small-scale societies conducted within these frameworks. More recent research has broadened from this initial focus to consider other factors which affect reproductive success, including phenomena which are not easily explained by fitness-maximisation models (e.g. the trend of decreased fertility with increased wealth in industrial societies) (Mace 2014; Sear et al. 2016).

3. The physiological mechanisms which underlie the importance of energetics act primarily on individual fecundity (the biological capacity to have children) rather than fertility (the actual production of children). However, in the natural fertility populations under discussion with no access to effective contraception, these are likely one and the same (Ellison 2008: 176).

4. Instances of obesity are the exception in the relationship between increased energy availability (as stored energy) and increased fertility, as obesity can impair ovarian function, and individual fecundity. However, obesity is rare in small-scale subsistence populations and is also likely of little relevance to the application of these principles to archaeological contexts (Ellison 2008:176).

5. Although the reproductive consequences of both the energy required and the dangers of death through hunting form the basis of assumptions that Palaeolithic women did not participate in hunting, there is some evidence among recent foragers for women hunting, including data which indicates that it does not always negatively impact fertility (e.g. Goodman et al. 1985). 


\section{Acknowledgments}

This research is part of the project "The Palaeolithic of Europe: a Demographic and Social Prehistory" funded by a Leverhulme Trust Early Career Fellowship (grant number: ECF-2016-128) held at University College London. A version of this paper was presented at the 2017 meetings of the Society for American Archaeology in Vancouver. Many thanks to Christina Collins, Sheila Kohring, Dominic Walker and two anonymous reviewers for helpful comments on earlier drafts. Special thanks are owed to John Robb for long discussions on many of the ideas presented in this paper, as well as specific critiques which have substantially improved the manuscript.

\section{Jennifer C. French UCL Institute of Archaeology 31-34 Gordon Square, London, WC1H OPY jennifer.french@ucl.ac.uk}

\section{References cited:}

Aiello, L. C. \& C. Key. 2002. Energetic consequences of being a Homo erectus female. American Journal of Human Biology 14(5): 551-565.

Aimers, J. \& D.M. Rutecki. 2016. Brave new world. Interpreting sex, gender, and sexuality in the past. The SAA Archaeological Record 16 (1): 12-17.

Andersen, K.K., A.Svensson, S.J. Johnsen, S.O. Rasmussen, M. Bigler, R. Röthlisberger, U. Ruth, M.-L. Siggaard-Andersen, J.P. Steffensen, D. Dahl-Jensen, B.M.Vinther \& H.B. Clausen. 2006. The Greenland Ice Core Chronology 2005, 15-42 ka. Part 1: Constructing the time scale. Quaternary Science Reviews 25 (23-24): 324657.

Arthur, K.W. 2010. Feminine knowledge and skill reconsidered: women and flaked stone tools. American Anthropologist 112 (2): 228-43.

Attenbrow, V. 2006. What's Changing: Population Size or Land-Use Patterns? Terra australis 21. Canberra: The Australian National University E Press. 
Baitzel, S. I. \& P.S. Goldstein. 2016. No country for old people: a paleodemographic analysis of migration dynamics in early Andean states. International Journal of Osteoarchaeology 26(6): 1001-1013.

Balme, J. \& S. Bowdler. 2006. Spear and digging stick. The origin of gender and its implications for the colonization of new continents. Journal of Social Archaeology 6 (3): 379-401.

Barshay-Szmidt, C., S. Costamagno, D. Henry-Gambier, V. Laroulandie, J-M. Pétillon, M. Boudadi-Maligne, D. Kuntz, M. Langlais \& J-B. Mallye. 2016. New extensive focused AMS 14C dating of the Middle and Upper Magdalenian of the western Aquitaine/Pyrenean region of France (ca.19-14 ka cal BP): proposing a new model for its chronological phases and timing of occupation. Quaternary International 414: 62-91.

Bentley, G.R. 1985. Hunter-gatherer energetics and fertility: a reassessment of the !Kung San. Human Ecology 13: 79-109.

Bentley, G.R. 1996. How did prehistoric women bear "Man the Hunter"?

Reconstructing fertility from the archaeological record, in Gender and Archaeology, ed. R.P. Wright. Philadelphia (PA): University of Pennsylvania Press, 23-51.

Binford, L.R. \& W.J. Chasko Jr. 1976. Nunamiut demographic history: a provocative case, in Demographic Anthropology, ed. E.B.W. Zubrow. Albuquerque (NM):

University of New Mexico Press, 63-143.

Blurton Jones, N.G. 1987. Bushman birth spacing: direct tests of some simple predictions. Ethology and Sociobiology 8: 183-203.

Blurton Jones, N.G. 2016. Demography and Evolutionary Ecology of Hadza HunterGatherers. Cambridge: Cambridge University Press.

Bocquet-Appel, J.- P. 2002. Paleoanthropological traces of a Neolithic Demographic Transition. Current Anthropology 43(4): 637 - 650.

Bocquet-Appel, J.-P. 2008. Explaining the Neolithic Demographic Transition, in The Neolithic Demographic Transition and its Consequences, eds. J.-P. Bocquet-Appel \& O. Bar-Yosef. Dordrecht: Springer, 35-55.

Bocquet-Appel, J.-P. 2011. When the world's population took off: the springboard of the Neolithic Demographic Transition. Science 333: 560 - 561. 
Bocquet-Appel, J.-P. \& C. Masset. 1982. Farewell to paleodemography. Journal of Human Evolution 11: 321-333.

Bocquet-Appel, J.-P \& O. Bar-Yosef. 2008. Prehistoric demographic in a time of globalization, in The Neolithic Demographic Transition and its Consequences, eds. J.-P. Bocquet-Appel \& O. Bar-Yosef. Dordrecht: Springer, 1-10.

Bolger, D. 2006. Gender and Human Evolution, in Handbook of Gender Archaeology, ed. S.M. Nelson. New York (NY): Altamira Press, 453-501.

Bolger, D. 2013. Introduction: gender prehistory- the story so far, in A Companion to Gender Prehistory ed. D. Bolger. Chichester: Wiley \& Sons, 1-19.

Brown, W.A. 2017. The past and future of growth rate estimation in demographic temporal frequency analysis: biodemographic interpretability and the ascendance of dynamic growth models. Journal of Archaeological Science 80: 96-108.

Brumbach, H.J. \& R. Jarvenpa. 2006. Gender dynamics in hunter-gatherer society: archaeological methods and perspectives, in Handbook of Gender in Archaeology, ed. S.M. Nelson. New York (NY): Altamira Press, 503-35.

Brumfiel, E.M. 2006. Methods in feminist and gender archaeology: a feeling for difference- and likeness, In Handbook of Gender Archaeology, ed. S.M. Nelson. New York (NY): Altamira Press, 31-58.

Burmeister, S. 2000. Archaeology and migration: approaches to an archaeological proof of migration. Current Anthropology 41 (4): 539-567.

Butte, N.F. \& J.C. King. 2005. Energy requirements during pregnancy and lactation. Public Health Nutrition 8 (7a): 1010-1027.

Chamberlain, A. 2006. Demography in Archaeology. Cambridge: Cambridge University Press.

Cohen, M.N. 2008. Implications of the NDT for worldwide health and mortality in prehistory, in in The Neolithic Demographic Transition and its Consequences, eds. J.-P. Bocquet-Appel \& O. Bar-Yosef. Dordrecht: Springer, 481-500.

Conkey, M.W. 1991. Contexts of action, contexts for power: material culture and gender in the Magdalenian, in Engendering Archaeology. Women and Prehistory, eds. J.M. Gero \& M.W. Conkey. Oxford: Blackwell, 57-92. 
Conkey, M.W. 2013. The future of gender in prehistoric archaeology, in A Companion to Gender Prehistory, ed. D. Bolger. Chichester: Wiley \& Sons, 108-20.

Conkey, M.W. \& J.M. Gero. 1997. Programme to practice: gender and feminism in archaeology. Annual Review of Anthropology 26: 411-37.

Conkey, M. W. \& J.D. Spector. 1984. Archaeology and the study of gender. Advances in Archaeological Method and Theory 7: 1-38.

Dobres, M-A. 1995. Gender and prehistoric technology: on the social agency of technical strategies. World Archaeology 27 (1): 25-49.

Dobres, M-A. 2004. Digging up gender in the earliest human societies, in $A$ Companion to Gender History, eds. T.A. Meade \& M.W.Wiesner-Hanks. Oxford: Blackwell, 211-26.

Downey, S.S., E. Bocaege, T. Kerig, K. Edinborough \& S. Shennan. 2014. The Neolithic demographic transition in Europe: correlation with juvenility index supports interpretation of the summed radiocarbon date probability distribution (SCDPD) as a valid demographic proxy. PloS One 9 (8):

https://doi.org/10.1371/journal.pone.0105730

Drennan, R.D., C. A. Berrey \& C.E. Petersen. 2015. Regional Settlement Demography in Archaeology. New York: Eliot Werner Publications Inc.

Dufour, D.L. and M.L. Sauther. 2002. Comparative and evolutionary dimensions of the energetics of human pregnancy and lactation. American Journal of Human Biology 14: 584-602.

Dunsworth, H.M., A.G. Warrener, T. Deacon, P.T. Ellison and H. Pontzer. 2012. Metabolic hypothesis for human altricality. Proceedings of the National Academy of Sciences USA 109 (38): 15212-16.

Early, J.D. \& T.N. Headland. 1998. Population Dynamics of a Philippine Rain Forest People. Gainesville (FL): University of Florida Press.

Ellison, P.T. 2001. On Fertile Ground. Cambridge (MA): Harvard University Press. Ellison, P.T. 2003. Energetics and reproductive effort. American Journal of Human Biology 15: 342-351.

Ellison, P.T. 2008. Energetics, reproductive ecology, and human evolution. PaleoAnthropology 2008: 172-200. 
Finlay, N. 2013. Gender and lithic studies in prehistoric archaeology, in A Companion to Gender Prehistory, ed. D. Bolger. Oxford: Wiley-Blackwell, 142-60.

Fleming, A. 2006. Post-processual landscape archaeology: a critique. Cambridge Archaeological Journal 16 (3): 267-80.

French, J. C. 2015. The demography of the Upper Palaeolithic hunter-gatherers of Southwestern France: A multi-proxy approach using archaeological data. Journal of Anthropological Archaeology 39: 193-209.

French, J. C. \& C. Collins. 2015. Upper Palaeolithic population histories of Southwestern France: a comparison of the demographic signatures of $14 \mathrm{C}$ date distributions and archaeological site counts. Journal of Archaeological Science 55: 12234 .

Frisch, R.E. 1994. The right weight: body fat, menarche, and fertility. Proceedings of the Nutrition Society 53: 113-29.

Frisch, R.E. 2002. Female Fertility and the Body Fat Connection. Chicago (IL): The University of Chicago Press.

Fritz, C., G. Tosello \& M.W. Conkey. 2016. Reflections of the identities and roles of the artists in European Palaeolithic societies. Journal of Archaeological Method and Theory 23: 1307-32.

Furholt, M. 2018. Massive migrations? The impact of recent aDNA studies on our view of Third Millennium Europe. European Journal of Archaeology 21 (2): 159-191.

Geller, P.L. 2009. Identity and difference: complicating gender in archaeology. Annual Review of Anthropology 38: 65-81.

Gero, J.M. 1991. Gender lithics: women's roles in stone tool production, in Engendering Archaeology. Women and Prehistory, eds. J.M. Gero \& M.W. Conkey. Oxford: Basil Blackwell, 163-93.

Ghisleni, L., A.M. Jordan \& E. Fioccoprile. 2016. Introduction to "binary binds": deconstructing sex and gender dichotomies in archaeological practice. Journal of Archaeological Method and Theory 23: 765-87.

Gifford-Gonzalez, D. 1993. You can hide, but you can't run: representation of women's work in illustrations of Palaeolithic life. Visual Anthropology Review 9 (1):2341. 
Gilchrist, R. 1999. Gender and Archaeology: Contesting the Past. New York (NY): Routledge.

Goodman, M.J., P.B. Griffen, A.A. Estioko-Griffen \& J.S. Grove. 1985. The compatibility of hunting and mothering among the Agta hunter-gatherers of the Philippines. Sex Roles 12 (11): 1199-1209.

Grove, M. 2009. Hunter-gatherer movement patterns : causes and contraints. Journal of Anthropological Archaeology 28, 222-33.

Hager, L.D. 1997. Sex and gender in Paleoanthropology, in Women in Human Evolution, ed. L.D. Hager. London : Routledge, 1-28.

Hames, R. \& P. Draper. 2004. Women's work, child care and helpers-at-the- nest in a hunter-gatherer society. Human Nature 15 (4): 319-41.

Hansen, C.W., P.S. Jensen \& C.V. Skovsgaard. 2015. Modern gender roles and agricultural history: the Neolithic inheritance. Journal of Economic Growth 20: 365-404.

Helle, S. \& S. Helama. 2007. Climatic variability and the population dynamics of historical hunter-gatherers: the case of Sami of Northern Finland. American Journal of Human Biology 19 (6): 844-53.

Henrich, J. 2004. Demography and cultural evolution: how adaptive cultural processes can produce maladaptive losses - the Tasmanian case. American Antiquity, 69(2): 197-214.

Hill, E. 1998. Gender-informed archaeology: the priority of definition, the use of analogy, and the multivariate approach. Journal of Archaeological Method and Theory 5 (1): 99-128.

Hill, K. \& A.M. Hurtado. 1996. Ache Life History. The Ecology and Demography of a Foraging People. New York (NY): Aldine de Gruyter.

Hinde, A. 2002. Demographic perspectives on human population dynamics, in Human Population Dynamics. Cross-Disciplinary Perspectives, eds. H. Macbeth \& P. Collinson. Cambridge: Cambridge University Press, 17-40.

Howell, N. 1976. Towards a uniformitarian theory of human paleodemography. Journal of Human Evolution 5: 25-40.

Howell, N. 1979. Demography of the Dobe!Kung. New York (NY): Academic Press. 
Howell, N. 2010. Life Histories of the Dobe!Kung. Food, Fatness, and Well-being over the Life-Span. Berkeley (CA): University of California Press.

Hull, K.L. 2011. Thinking small: hunter-gatherer demography and culture change, in Hunter-Gatherer Archaeology as Historical Process, eds. K.E. Sassaman \& D.H. Holly Jr. Tuscon (AZ): The University of Arizona Press, 34-54.

Jasienka, G. 2003. Energy metabolism and the evolution of reproductive suppression in the human female. Acta Biotheoretica 51: 1-18.

Joyce, R.A. 2008. Ancient Bodies, Ancient Lives. Sex, Gender, and Archaeology. London: Thames \& Hudson.

Keeley, L.H. 2010. The probable sexual division of labor in Magdalenian hide working, in, The Magdalenian Household. Unravelling Domesticity, eds. E. Zubrow, F. Audouze, \& J.G. Enloe. Albany (NY): State University of New York Press, 227-34.

Kelly, R.L. 2013. The Lifeways of Hunter-Gatherers. Cambridge: Cambridge University Press.

Kelly, R.L., T.A. Surovell, B.N. Shuman \& G.M. Smith. 2013. A continuous climatic impact on Holocene human population in the Rocky Mountains. Proceedings of the National Academy of Sciences USA 110 (2): 443-447.

King, C.L., A.R. Millard, D.R. Gröcke, V.G. Standen, B. T. Arriaza \& S.E. Halcrow. 2017. A comparison of using bulk and incremental isotopic analyses to establish weaning practises in the past. STAR: Science E Technology of Archaeological Research 3 (1): 126-134.

Kintigh, K.W., J.H. Altschul, M.C. Beaudry, R.D. Drennan, A.P. Kinzig, T.A. Kohler, W.F. Limp, H.D.G. Macschner, W.K. Michener, T.R. Pauketat, P. Peregrine, J.A. Sabloff, T.J. Wilkinson, H.T. Wright \& M.A. Zeder. 2014. Grand challenges for archaeology. American Antiquity 79 (1): 5-24.

Kramer, K.L. \& R.D. Greaves. 2007. Changing patterns of infant mortality and maternal fertility among Pumé foragers and horticulturalists. American Anthropologist 109 (4): 713-26.

Kramer, K.L. \& G.P. McMillan. 2006. The effect of labor-saving technology on longitudinal fertility changes. Current Anthropology 47 (1): 165-172. 
Lambert, P.M. 2009. Health versus fitness: competing themes in the origins and spread of agriculture. Current Anthropology 50 (5): 603-8.

Langlais, M. 2011. Processes of change in Magdalenian societies in the Pyrenean isthmus (20-16 ky cal BP). Antiquity 85: 715-28.

Langlais, M., A. S. Caux, V. Delvigne, L. Gourc, C. Normand, M. Sánchez de la Torre. 2016. Lithic tool kits: a metronome of the evolution of the Magdalenian in Southwest France (19,000-14,000 cal BP). Quaternary International 414: 92-107.

Langley, M.C., J-M. Pétillon \& M. Christensen. 2016. Diversity and evolution of osseous hunting equipment during the Magdalenian (21,000-14,000 cal BP), in Osseous Projectile Weaponry, ed. M.C. Langley. Dordrecht: Springer, 143-59.

Mace, R. 2014. When not to have another baby: an evolutionary approach to low fertility. Demographic Research 30: 1074-1096.

Marlowe, F. 2001. Male contribution to diet and female reproductive success among foragers. Current Anthropology 42: 755-59.

McCoid, C.H \& L.D. McDermott. 1996. Towards decolonizing gender. Female vision in the Upper Palaeolithic. American Anthropologist 98 (2): 319-26.

McFadden, C. \& M.F. Oxenham. 2018. The D0-14/D ratio: A new paleodemographic index and equation for estimating total fertility rates. American Journal of Physical Anthropology 165(3): 471-479.

Meindl, R.S. \& K.F. Russell. 1998. Recent advances in method and theory in Paleodemography. Annual Review of Anthropology 27: 375-399.

Mussi, M. 2007. Women of the middle latitudes. The earliest peopling of Europe from a female perspective, in Guts and Brains. An Integrative Approach to the Hominin Record ed. W. Roebroeks. Leiden: Leiden University Press, 165-83.

Naudinot, N., A. Tomasso, C. Tozzi \& M. Peresani. 2014. Changes in mobility patterns as a factor of $14 \mathrm{C}$ date density variation in the Late Epigravettian of Northern Italy and Southeastern France. Journal of Archaeological Science 52: 578-90.

Owen, L.R. 2005. Distorting the Past. Gender and the Division of Labour in the European Upper Palaeolithic. Tübingen: Kerns Verlag. 
Page, A.E., S. Viguier, M. Dyble, D. Smith, N. Chaudhary, G.D. Salali, J. Thompson, L. Vinicius, R. Mace \& A.B. Migliano. 2016. Reproductive trade-offs in extant huntergatherers suggest adaptive mechanism for the Neolithic expansion. Proceedings of the National Academy of Sciences USA 113(17): 4694-99.

Panter-Brick, C. 1997. Women's work and energetics: a case study from Nepal, in The Evolving Female: A Life-History Perspective, eds. M.E. Morbeck, A. Galloway \& A.L. Zihlman. Princeton (NJ): Princeton University Press, 233-41.

Pennington, R. 2001. Hunter-Gatherer demography, in Hunter-Gatherers: An Interdisciplinary Perspective eds. C. Panter-Brick, R.H. Layton \& P. Rowley-Conwy. Cambridge: Cambridge University Press, 170-204.

Peterson, J. 2010. Domesticating gender: Neolithic patterns from the southern Levant. Journal of Anthropological Archaeology 29: 249-64.

Pétillon, J-M. 2016. Technological evolution of hunting implements among Pleistocene hunter-gatherers: osseous projectile points in the middle and upper Magdalenian (19-14 ka cal BP). Quaternary International 414: 108-34.

Porčič, M. \& M. Nikolić. 2016. The approximate Bayesian computation approach to reconstructing population dynamics and size from settlement data: demography of the Mesolithic-Neolithic transition at Lepenski Vir. Archaeological and Anthropological Sciences 8 (1): 169-86.

Powell, A., S. Shennan \& M.G. Thomas. 2009. Late Pleistocene demography and the appearance of modern human behavior. Science, 324(5932), 1298-1301.

Price, T.D., J.H. Burton \& R.A. Bentley. 2002. The characterization of biologically available strontium isotope ratios for the study of prehistoric migration. Archaeometry 44 (1): 117-135.

Read, D.W. 2003. Emergent properties in small-scale societies. Artificial Life 9: 419-34.

Rick, J.W. 1987. Dates as data: an examination of the Peruvian preceramic radiocarbon record. American Antiquity 52 (1): 55-73.

Riley, N.E. 1998. Research on Gender in Demography: Limitations and constraints. Population Research and Policy Review 17: 521-38.

Riley, N.E. 1999. Challenging Demography: Contributions from Feminist theory. Sociological Forum 14 (3): 369-97. 
Riley, N.E. 2005. Demography of Gender, in Handbook of Population ed. D.L Poston \& M. Micklin. Dordrecht: Springer, 109-41.

Roth, E.A. 1985. A note on the demographic concomitants of sedentism. American Anthropologist 87 (2): 380-2.

Roth, E.A. 2004. Culture, Biology, and Anthropological Demography. Cambridge: Cambridge University Press.

Sattenspiel, L. \& H. Harpending. 1983. Stable populations and skeletal age. American Antiquity 48 (3): 489-498.

Sear, R., D.W. Lawson, H. Kaplan \& M.K. Shenk. 2016. Understanding variation in human fertility: what can we learn from evolutionary demography? Philosophical Transactions of the Royal Society B 371: 20150144. doi: 10.1098/rstb.2015.0144.

Shennan, S. 2002. Genes, Memes and Human History. Darwinian Archaeology and Cultural Evolution. London: Thames \& Hudson.

Shennan, S. 2018. The First Farmers of Europe: An Evolutionary Perspective. Cambridge: Cambridge University Press.

Shennan, S., S.S. Downey, A. Timpson, K. Edinborough, S. Colledge, T. Kerig, K. Manning \& M.G. Thomas. 2013. Regional population collapse followed initial agriculture booms in mid-Holocene Europe. Nature Communications 4. doi: 10. 1038/ncomms3486.

Snodgrass, J.J. \& W.R. Leonard. 2009. Neanderthal energetics revisited: insights into population dynamics and life history evolution. PaleoAnthropology 2009: 220-237.

Snow, D.R. 2006. Sexual dimorphism in Upper Palaeolithic hand stencils. Antiquity 80: 390-404.

Spielmann, K.A. 1989. A review: dietary restrictions on hunter-gatherer women and the implications for fertility and infant mortality. Human Ecology 17 (3): 321-45.

Stratton, S. 2016. "Seek and you shall find". How the analysis of gendered patterns in archaeology can create false binaries: a case study from Durankulak. Journal of Archaeological Method and Theory 23: 854-69. 
Tsutaya, T. \& M. Yoneda. 2015. Reconstruction of breastfeeding and weaning practices using stable isotope and trace element analyses: a review. Yearbook of Physical Anthropology 156: 2-21.

United Nations Children's Fund and World Health Organisation. 2004. Low Birthweight. Country, Regional and Global Estimates. UNICEF, New York, 2004.

Van Gelder, L., \& K. Sharpe. 2009. Women and girls as Upper Palaeolithic cave 'artists': deciphering the sexes of finger fluters in Rouffignac Cave. Oxford Journal of Archaeology 28 (4): 323-33.

Vanhaeren, M., \& F. d'Errico. 2005. Grave goods from the Saint-Germain-la-Rivière burial: evidence for social inequality in the Upper Palaeolithic. Journal of Anthropological Archaeology 24: 117-34.

Whitehouse, R.D. 2007. Gender archaeology and the archaeology of women, in Archaeology and Women. Ancient and Modern Issues, eds. S. Hamilton, R.D. Whitehouse \& K.I. Wright. Walnut Creek (CA): Left Coast Press, 27-40.

Williams, A.N. 2012. The use of summed radiocarbon probability distributions in archaeology: a review of methods. Journal of Archaeological Science 39: 578-89.

Wilmsen, E.N. 1982. Studies in diet, nutrition, and fertility among a group of Kalahari bushmen of Botswana. Social Science Information 21: 95-125.

Wood, J.W. 1990. Fertility in anthropological populations. Annual Review of Anthropology 19: 211-42.

Wylie, A. 1991. Gender theory and the archaeological record: why is there no archaeology of gender? in Engendering Archaeology. Women and Prehistory eds. J.M.Gero \& M.W. Conkey. Oxford: Blackwell, 31-54.

Zahid, H.J., E. Robinson \& R.L. Kelly. 2016. Agriculture, population growth, and statistical analysis of the radiocarbon record. Proceedings of the National Academy of Sciences 113 (4): 931-935.

Zihlman, A. 1997. The Palaeolithic glass ceiling, in Women in Human Evolution, ed. L.D. Hager. London : Routledge, 91-113.

Zihlman, A. 2013. Engendering human evolution, in A Companion to Gender Prehistory, ed. D. Bolger. Chichester: Wiley \& Sons, 23-44. 


\section{About the author:}

Jennifer French completed her PhD in Palaeolithic Archaeology at the University of Cambridge and is currently a Leverhulme Trust Early Career Fellow based the UCL Institute of Archaeology. Her research interests include archaeological demography, hunter-gatherer studies, and the methodological and theoretical challenges of the archaeology of archaic hominins. Her work on Palaeolithic demography has appeared in various journals including Journal of Archaeological Method and Theory, Journal of Anthropological Archaeology, and Science.

Tables: 


\begin{tabular}{|c|c|c|c|}
\hline & Relevant factors & $\begin{array}{c}\text { Physical } \\
\text { environment }\end{array}$ & Social environment \\
\hline Energy input & $\begin{array}{l}\text { - Food } \\
\text { - Nutrition }\end{array}$ & $\begin{array}{l}\text {-Type, } \\
\text { availability, } \\
\text { density and } \\
\text { distribution of } \\
\text { food resources } \\
\text { (with possible } \\
\text { seasonal effects) }\end{array}$ & $\begin{array}{l}\text {-Technology available to procure food } \\
\text {-Technology available to process and } \\
\text { store food } \\
\text {-Economic base and cultural notions of } \\
\text { what constitutes "food" } \\
\text {-Social access to food resources; } \\
\text { restrictions on food due to taboos or } \\
\text { preferential access by certain sub- } \\
\text { groups (social status, gender, age) } \\
\text {-Size of group/family that share } \\
\text { resources }\end{array}$ \\
\hline Energy output & $\begin{array}{l}\text {-Mobility } \\
\text {-Workload } \\
\text {-Physical } \\
\text { activity levels }\end{array}$ & $\begin{array}{l}\text {-Environment } \\
\text { type and terrain } \\
\text {-Distribution of } \\
\text { resources (food, } \\
\text { water, raw } \\
\text { materials) }\end{array}$ & $\begin{array}{l}\text {-Type and degree of mobility } \\
\text { (sedentary/residentially/logistically } \\
\text { mobile; distances travelled and } \\
\text { frequency of movement) } \\
\text {-Economic base and associated tasks } \\
\text { (e.g. hunting and gathering vs. } \\
\text { horticulture) } \\
\text {-Division of labour and tasks (by } \\
\text { gender, age, social status) } \\
\text {-Degree of help available in conducting } \\
\text { economic and/or domestic tasks } \\
\text { (technological assistance, helpers) } \\
\text {-Size of group/family that must be } \\
\text { cared/provisioned for via economic } \\
\text { and domestic tasks }\end{array}$ \\
\hline
\end{tabular}

Table 1. Examples of key features of the social and physical environment which influence women's energy availability. 
Figure 1. Schematic of the simplified physiological relationships between women's energy, fertility, infant mortality and population growth/decline.

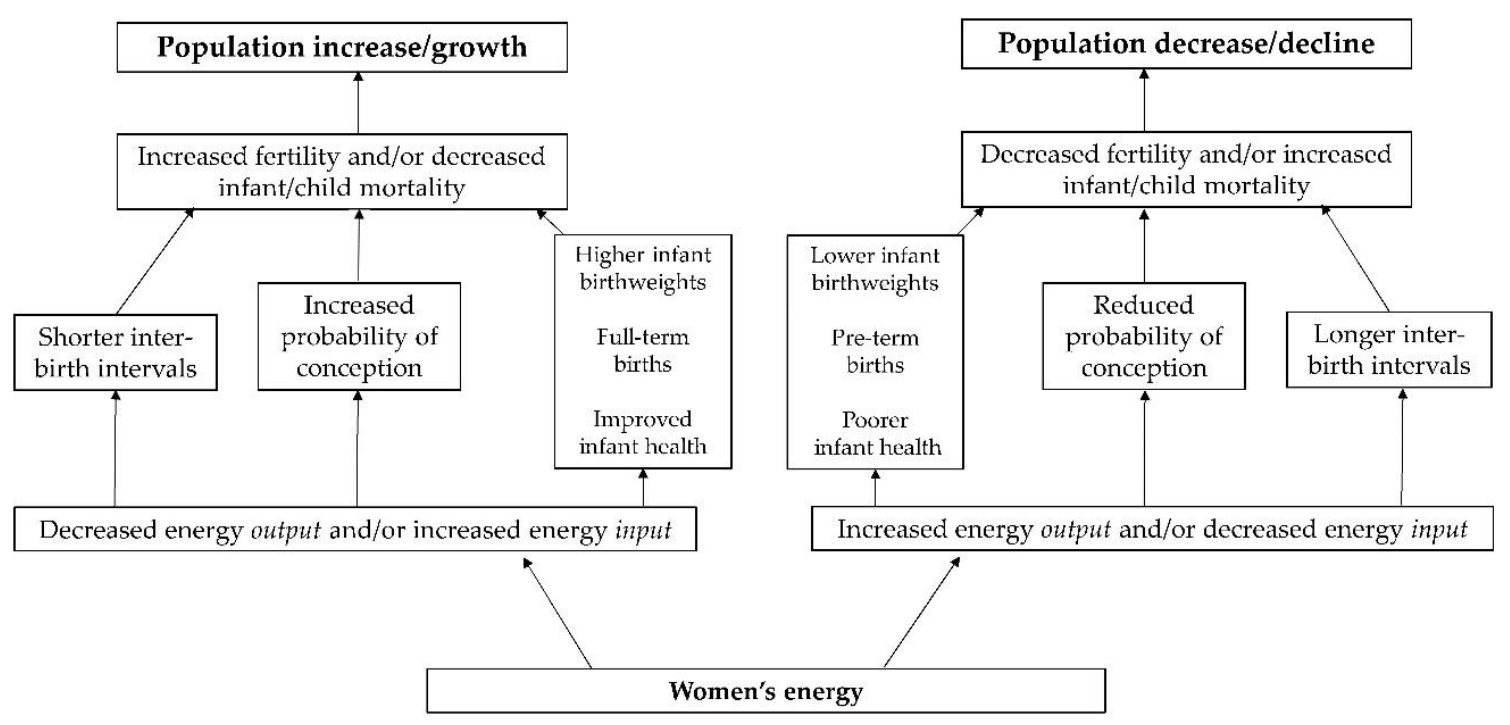




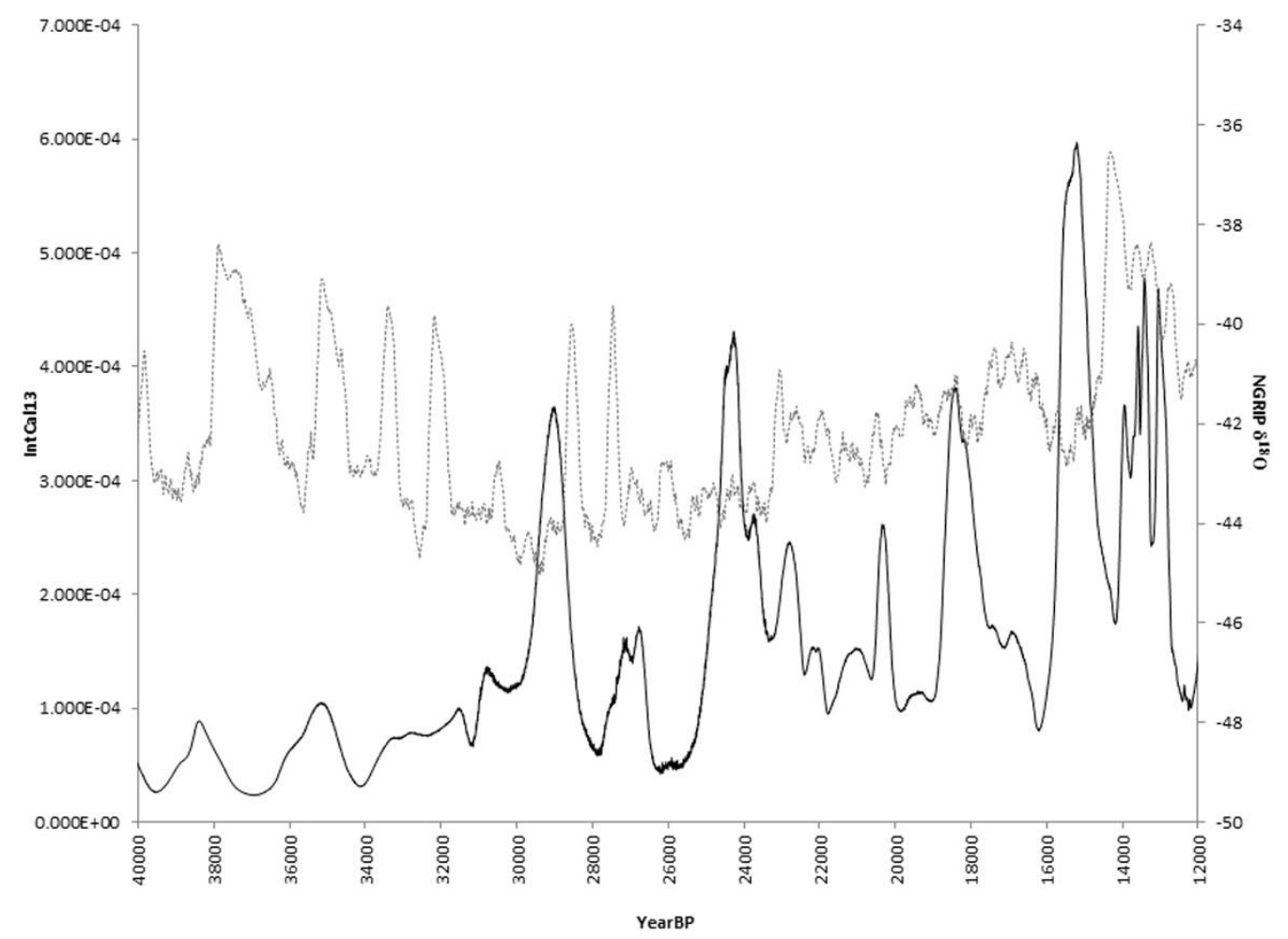

Figure 2. Demographic fluctuations of relative population size during the Upper Palaeolithic of southwestern France. Population fluctuations are indicated by a summed probability distribution of radiocarbon dates from the region calibrated with IntCal 13 (solid line). These are compared with the NGRIP $\delta 18 \mathrm{O}$ curve (dotted line, smoothed with a moving average filter with 200-year window). (Figure from French \& Collins 2015, fig. 8. See French $\mathcal{E}$ Collins 2015 for details of the methodology.) 